\title{
Endemik Sarıkız Çayı Sideritis trojana Bornm Bitkisinin Çelikle Çoğaltım Şartlarının Belirlenmesi
}

\author{
Onur Sinan Türkmen
}

Çanakkale Onsekiz Mart Üniversitesi Ziraat Fakültesi Tarla Bitkileri Bölümü, 17020/Çanakkale Sorumlu yazar: onurturkmen@comu.edu.tr

Geliş Tarihi: 19.10.2018

Kabul Tarihi: 10.01.2019

\section{$\ddot{\mathbf{O} z}$}

Sarıkız çayı Kazdağı'na özgü bir endemik bitkidir. Sarıkız çayı bitkisi, tıbbi ve aromatik amaçla yoğun bir şekilde toplanarak kullanılması nedeniyle, yok olma tehlikesi ile karşı karşıyadır. Bu bitkinin en uygun köklendirme yönteminin tespit edilip yörede yetiştirilmesi ile yok olması önüne geçilebilir. Bu çalışmada sarıkız çayı bitkisinin çelikle çoğaltımı amacıyla üç farklı köklendirme ortamı (kum, hindistancevizi kabuğu ve perlit) ile dört farklı doz İBA hormonu (0-1000-2000 ve 4000 ppm) uygulanmıştır. Çalışma sonunda en yüksek köklenme oranı (\%57) ile 1000ppm İBA uygulanan kum ortamında ulaşılmıştır. Bu çalışma ile Sarıkız çayı bitkisi Sideritis trojana'nın çelikle çoğaltımı yapılarak koruma altına alınması sağlanmıştır.

Anahtar Kelimeler: Kazdağı, İndol-3-Butrik Asit, Kültür, Nesli Tükenmek, Köklendirme

\section{Determination of Suitable Cutting Propagation Conditions for Endemic Sarıkız Tea Sideritis trojana Bornm}

\section{Abstract}

Sarıkız tea is an endemic plant is unique to Ida Mountain. Due to medical and aromatic usage, the plant is under endanger of extinction. Determination of the most appropriate rooting method and cultivation in native distribution area can be prevent of extinction. In this study, four different doses of IBA (0-1000-2000 and $4000 \mathrm{ppm}$ ) and three different rooting media (sand, cocopeat and perlite) were applied. The highest rooting ratio (57\%) was reached with $1000 \mathrm{ppm}$ IBA sand. In conclusion Sarıkı tea plant Sideritis trojana was cultivated and protected by cutting propagation method.

Keywords: Ida Mountain, Indole-3-Butyric Acid, Cultivation, Extinction, Rooting

\section{Giriş}

Lamiaceae familyası altında yer alan dağ çayı Sideritis in Türkiye'de yayılım gösteren 46 türü bulunmaktadır (Şahin ve ark., 2005). Marmara ile Ege bölgesi arasında geçit oluşturan Kazdağı yükseltisinde bulunan 55 endemik takson ve Kazdağı'na özgü 31 endemik bitki türünden birisi de Sarıkız çayı bitkisi Sideritis trojana'dır (Uysal 2010; Öztürk ve ark., 2011). Sarıkız çayı, Kazdağı'nın Bakanlar Kurulu 93/4243 say1lı kararı ile Milli Park ilan edilerek koruma altına alınan 21.450 hektarlık bölümü içerisinde yer alsa da kaçak toplanarak yok olma tehlikesi altındadır (Uysal, 1991; Satıl ve ark., 2006; Uysal, 2010). Trojana çok yıllık çalı formunda otsu yapıdadır. Sarıkız çayı bitkisini diğer türlerden ayıran en belirgin özelliği yaprağın her iki yanında bulunan yünsü beyaz tüyleri ve koyu sarı çiçekleridir (Uysal ve ark., 1991).

Sideritis trojana bitkisi doğal yayılış alanları, yüksek eğimdeki ana kayaçta sınırlı toprak birikintileridir. Sideritis trojana'nın doğal yayılış gösterdiği ortamlar organik madde açısından zengin olsa da bitki besin madde varlığı açısından yüksek verimlilikte olmayıp geçirgen yapıdadır. Bitki kökleri yüzlek yayılım gösterip havadar ortam isteği bulunur. Sideritis trojana bitkisinin kısmi alkali, kumlu tınlı, düşük tuz ve kireçli fosfor ve organik madde açısından zengin alanlarda potasyum bakımından fakir topraklarda yetiştiği ifade edilmiştir (Uysal ve ark., 1991).

Sarıkız çayının yok olma tehlikesi altında olmasının en önemli nedeni temmuz ağustos aylarında açan sarıçiçeklerinin tıbbi amaçla ve çay yapımında kullanılıyor olmasından ileri gelmektedir. Sarıkız çayı çiçekleri \%2-5 oranında infüzyon şeklinde demlenerek kullanılması öngörülürken, halk arasında göğüs, böbrek hastalıkları, peptik, soğuk algınlığı, böbrek antimikrobiyal 
ve mide rahatsızlıklarında tıbbi amaçlı ve günlük aromatik çay olarak kullanılmaktadır (Çelik ve ark., 2008; Selvi ve ark., 2013).

Sarıkız çayı yalnızca çay yapımında değil farklı endüstri uygulamaları açısından da ümit var bir bitki kaynağıdır. Önal ve ark., 2015 yılında yayınladıkları bir çalışmada Sarıkız çayının yün kumaşların doğal yöntemlerle renklendirilmesinde söğüt ekstraktına alternatif bir materyal olabileceği sonucuna varılmıştır. Bir diğer çalışmada ise Sarıkız çayı bitkisinden elde edilen esansiyel yağın düşük dozlarının bile ülsere yol açan $H$. pylori bakterisine karşı etkili olduğu tespit edilmiştir (Kırmızıbekmez ve ark., 2017). Sideritis spp. ektraktının hafizayı güçlendirerek Alzheimer hastalığında öğrenme yeteneğini arttırdığına yönelik ümit var sonuçlar elde edilmiştir (Hofrichter ve diğ., 2016). Sarıkız çayının aroması adaçayına benzese de kendine has aroma ve kokusu bulunmaktadır. Siderol, sideri-diol, 7-epicandicandiol, isocandol B, candol A acetat bileşiklerini içerdiği bilinirken ent-kaurane (ent-7-acetoxy-15,16-epoxykaurane) ve ent-pimarane (ent-2-hydroxy8(14),15-pimaradiene) diterpenleri ilk olarak Sarıkız çayından izole edilmiştir (Topçu ve ark., 2001).

Endemik bitkilerin ex situ korunmasında mikroklonal üretim önemli olsa da sarıkız çayının doku kültürü yöntemiyle çoğaltımı üzerine yapılan çalışmada başarı sağlanamamıştır. Bu durumun sebebi Sarıkız çayı'nın içerdiği yoğun polifenolik bileşiklerden ötürü doku kültürü çoğaltımında nekrosis ve kallus kararması olarak belirtilmiştir (Çördük ve Akı, 2011). Bu sebeple Sarıkız çayı endemik bitkisinin çelikle çoğaltımı yok olma tehlikesine karşı korunması açısından önemli bir yöntemdir (Fay, 1992).

Sarıkız çayı 1400-1770 m rakımlı alanlarda yayılış göstermektedir ve bu alan Kazdağı Milli Park Sınırları içerisinde yer almaktadır. Bu bölgeye ulaşım zorluğu gerekse bitki popülasyonunun seyrekleşmesi nedeniyle Kazdağı'nın Çanakkale yamaçlarındaki köylerde bazı köylüler tarafından kültüre alınmıştır. Diğer yandan doğal floradan toplanan bitki örneklerinde alüminyum, arsenik ve kurşun ağır metal içeriklerinin çok yoğun olduğu, kültüre alınan bitkilerde bu değerlerin çok düşük olduğu sonucuna varılmıştır (Aksu ve Türkmen, 2017). Bu durumun temel nedeni serpantin içeriği yüksek ana kayadan ağır metal kontaminasyonu olması mümkündür (Leblebici ve Çelik, 2014).

Sarıkız çayı bitkisinin ekonomik üretimin sağlanması ile tıbbi ve aromatik amaçla kullanımının yaygınlaşması yanında ilaç ve doğal boya endüstrisindeki kullanımının da önünün açılması mümkündür. Ancak sınırlı bir alanda yayılım gösteren ve yok olma tehlikesi altındaki bu bitkinin doğadan toplanarak bu ihtiyaca cevap vermesi mümkün değildir. Sarıkız çayı bitkisinin kültüre alınması ve doğal yayılış gösterdiği alanlar dışında bu bitkiyi toplayarak yaşamını sürdüren köylüler tarafından üretilmesi ayrıca ekonomik ve sosyokültürel bir katkı sağlayabilir.

$\mathrm{Bu}$ çalışmada Kazdağı endemiği olan sarıkız çayı bitkisinin çelikleme yöntemiyle çoğaltımı için en uygun köklendirme ortam materyali ve büyüme düzenleyici dozunun belirlenmesi amacıyla kum, hindistan cevizi kabuğu ve perlit ile Indol-3 butrik asit hormonunun 4 farklı dozu $(0,1000,2000$ ve 4000 ppm) uygulanarak en uygun köklendirme ortamının belirlenmesi amaçlanmıştır.

\section{Materyal ve Yöntem}

Çalışma 2018 yılında Çanakkale Onsekiz Mart Üniversitesinde yürütülmüş̧ür. Denemeler 3 tekerrürlü olarak her tekerrürde 10 bitki olacak şekilde kurulmuştur. Denemede kullanılacak çoğaltım materyalleri Kazdağı'nın kuzey batı yamacında bulunan Bayramiç ilçesinde kültür bahçesinden temin edilmiştir. Çanakkale deniz seviyesinde rakıma sahip olması sebebiyle de bitkinin doğal yaşam alanı olan 1400-1770 metre rakımın oldukça dışındadır. Apikal ve iki lateral meristem içeren $5 \mathrm{~cm}$ uzunluğundaki bitki parçaları kesilip bitki büyüme düzenleyicisi ile muamele edilerek köklendirme ortamlarına yerleştirilmiştir. Köklendirme ortamları $51 \times 37 \times 20 \mathrm{~cm}$ ebatlarındaki genişletilmiş polistren koliler üç bölüme ayrılarak her birisine köklendirme ortamları kum $(\mathrm{K})$, kokopeat $(\mathrm{C})$ ve perlit $(\mathrm{P})$ yerleştirilerek oluşturulmuştur. Kontrol grubu olarak da hormon uygulanmayan bitki parçaları aynı köklendirme ortamlarından oluşan köklendirme kaplarına yerleştirilmiştir. Çelikler, \%96'lık etil alkol ile seyreltilmiş $1000-2000$ ve 4000 İBA hormon solüsyonuna 5 sn boyunca daldırılıp hizlica köklendirme ortamlarına yerleştirilmiştir. Denemeler bitki materyallerinin temin edildiği 9 Mart 2018 tarihinde tesadüf parselleri deneme desenine uygun olarak kurulmuş, doğrudan güneş olmayan bir alana yerleştirilerek düzenli aralıklarla sulanmış ve 90 gün sonunda veriler elde edilmiştir.

Çalışma sonunda 90. günde canlılık yüzdesi (\%), toplam bitki ağırlı̆̆ı (g), ana kök meristeminden apikal meristeme kadar olan bitki boyu $(\mathrm{cm})$, kök boğazından ana kök meristemine 
kadar olan kök uzunluğu $(\mathrm{cm})$, toplam yaprak sayısı (adet), köklenme yüzdesi (\%) verileri elde edilmiştir. Veriler SAS istatistik programında PROC GLM varyans analizine tabi tutulmuştur. Her uygulama ayrı değerlendirilerek asgari önem fark (LSD 0,05) metoduna göre önem fark1 belirlenmiştir.

\section{Bulgular ve Tartışma}

Farklı İBA konsantrasyonları ve köklendirme ortam uygulamalarının Sarıkız çayı bitkisi köklendirme ve erken vejetatif gelişimi üzerine önemli farklılıklar oluşturduğu gözlenmiştir. Sarıkız çayında İBA uygulamasını takip eden 90 gün sonunda elde edilen verilerde, düşük dozda uygulanan İA hormon düzeylerindeki canlılık yüzdesinin yüksek olduğu görülmektedir (Çizelge 1).

Çizelge 1. Sarıkız çayında çelikleme için uygun ortam ve farklı İBA hormon dozlarının incelenen özellikler üzerine etkisi $\left(\mathrm{LSD}_{0,05}\right)$

\begin{tabular}{|c|c|c|c|c|c|c|c|c|}
\hline & \multicolumn{4}{|c|}{ Bitki ağırlığı (g) } & \multicolumn{4}{|c|}{ Kök uzunluğu (cm) } \\
\hline & Perlit & Kum & Coco. & Ort. & Perlit & Kum & Coco. & Ort. \\
\hline Hormonsuz & $0,58 \mathrm{~B}$ & $0,42 \quad \mathrm{~B}$ & $0,27 \quad \mathrm{~B}$ & 0,42 & $0,00 \quad \mathrm{~B}$ & $0,23 \quad \mathrm{~B}$ & $0,00 \mathrm{~B}$ & 0,08 B \\
\hline $1000 \mathrm{ppm}$ & $0,53 \mathrm{~B}$ & $1,26 \mathrm{~A}$ & $0,41 \quad \mathrm{~B}$ & 0,73 & $1,24 \mathrm{~B}$ & $4,89 \mathrm{~A}$ & $0,11 \mathrm{~B}$ & $2,08 \mathrm{~A}$ \\
\hline $2000 \mathrm{ppm}$ & $0,37 \mathrm{~B}$ & $0,85 \mathrm{AB}$ & $0,39 \quad \mathrm{~B}$ & 0,54 & $2,52 \mathrm{AB}$ & $2,32 \mathrm{AB}$ & $0,82 \mathrm{~B}$ & $1,89 \mathrm{~A}$ \\
\hline $4000 \mathrm{ppm}$ & $0,27 \mathrm{~B}$ & $0,51 \quad \mathrm{~B}$ & $0,86 \mathrm{AB}$ & 0,55 & $2,24 \mathrm{AB}$ & $1,80 \mathrm{~B}$ & $1,42 \mathrm{~B}$ & $1,82 \mathrm{~A}$ \\
\hline \multirow[t]{3}{*}{ Ortalama } & 0,44 & 0,76 & 0,48 & & $1,50 \mathrm{AB}$ & $2,31 \quad A$ & 0,59 B & \\
\hline & \multicolumn{4}{|c|}{ Yaprak sayısı (adet) } & \multicolumn{4}{|c|}{ Bitki boyu (cm) } \\
\hline & Perlit & Kum & Coco. & Ort. & Perlit & Kum & Coco & Ort. \\
\hline Hormonsuz & $4,50 \mathrm{~A}-\mathrm{C}$ & $4,60 \mathrm{AB}$ & $4,08 \mathrm{~A}-\mathrm{D}$ & $4,39 \quad A$ & $1,52 \mathrm{~B}-\mathrm{D}$ & 1,42 B-D & $1,50 \mathrm{~B}-\mathrm{D}$ & $1,48 \mathrm{~B}$ \\
\hline $1000 \mathrm{ppm}$ & $4,43 \mathrm{~A}-\mathrm{C}$ & $6,12 \mathrm{~A}$ & $4,80 \mathrm{AB}$ & 5,11 A & $3,73 \mathrm{AB}$ & $4,99 \mathrm{~A}$ & $2,86 \mathrm{~A}-\mathrm{C}$ & 3,86 A \\
\hline $2000 \mathrm{ppm}$ & $1,67 \mathrm{~B}-\mathrm{D}$ & $3,53 \mathrm{~A}-\mathrm{D}$ & $1,20 \mathrm{D}$ & 2,13 BC & 1,69 B-D & $1,85 \mathrm{~B}-\mathrm{D}$ & $0,14 \mathrm{D}$ & $1,23 \mathrm{~B}$ \\
\hline $4000 \mathrm{ppm}$ & $1,42 \mathrm{CD}$ & 1,73 B-D & 2,75 B-D & $1,97 \mathrm{C}$ & 1,16 B-D & $0,68 \mathrm{CD}$ & $0,89 \mathrm{CB}$ & 0,91 B \\
\hline \multirow[t]{3}{*}{ Ortalama } & $\mathbf{3 , 0 0}$ & 3,99 & 3,21 & & 2,02 & 2,24 & 1,35 & \\
\hline & \multicolumn{4}{|c|}{ Canlılık } & \multicolumn{4}{|c|}{ Köklenme yüzdesi } \\
\hline & Perlit & Kum & Coco. & Ort. & Perlit & Kum & Coco. & Ort. \\
\hline Hormonsuz & $0,93 \mathrm{~A}$ & 0,47 B-E & $0,63 \mathrm{~A}-\mathrm{C}$ & 0,68 & $0,00 \mathrm{D}$ & $0,00 \mathrm{D}$ & $0,00 \mathrm{D}$ & 0,00 B \\
\hline $1000 \mathrm{ppm}$ & $0,53 \mathrm{CB}$ & $0,80 \mathrm{AB}$ & $0,77 \mathrm{AB}$ & 0,70 & $13,00 \mathrm{~B}-\mathrm{D}$ & $57,00 \mathrm{~A}$ & $0,00 \mathrm{D}$ & 23,33 A \\
\hline $2000 \mathrm{ppm}$ & $0,43 \mathrm{~B}-\mathrm{E}$ & 0,47 B-E & $0,13 \mathrm{E}$ & 0,34 & 0,20 B-D & $0,30 \mathrm{~B}$ & $0,13 \mathrm{~B}-\mathrm{D}$ & $21,00 \mathrm{~A}$ \\
\hline $4000 \mathrm{ppm}$ & $0,60 \mathrm{~A}-\mathrm{C}$ & $0,17 \mathrm{DE}$ & $0,30 \mathrm{C}-\mathrm{E}$ & 0,36 & $0,03 \mathrm{CB}$ & $0,23 \mathrm{BC}$ & $0,27 \mathrm{~B}$ & $17,78 \mathrm{~A}$ \\
\hline Ortalama & $\mathbf{0 , 6 3}$ & 0,48 & 0,46 & & 9,17 B & $27,50 \mathrm{~A}$ & $10,83 \mathrm{~B}$ & \\
\hline
\end{tabular}

Hormon seviyeleri ve köklendirme ortamlarının kök uzunluğu ve köklenme yüzdesi üzerine önemli bir etkisi var iken, yaprak sayısı ve bitki boyu özellikleri bakımından yalnızca hormon seviyelerinin etkili olduğu belirlenmiştir (Çizelge 1). İncelenen özellikler bakımından hormon seviyeleri x köklendirme ortam özellikleri bakımından interaksiyon önemli bulunmuştur (Çizelge 1). En yüksek canlılık oranına sirasıyla P hormonsuz (\%93), K1000 (\%80) ve K1000 (\%77) uygulamalarında ulaşılmıştır (Çizelge 1). Ancak köklenme gerçekleşmeyen bitkilerde beslenme gerçekleşmediğinde ölümler meydana geleceğinden canlılık oranlarının köklenme yüzdelerinin birlikte incelenmesi yararlı olacaktır. Bu açıdan bakıldığında K1000 ve K2000 ve C4000 uygulamalarının köklenme yüzdeleri bakımından sırasıyla $\% 57, \% 30$ ve \%27 oranlarla öne çıktığı görülmüştür.

Köklenmenin en yüksek gerçekleştiği K1000, K2000 ile C4000 uygulamalarının en yüksek bitki ağırlığına ulaşıldığı görülmüştür. Kök uzunluğu ve yaprak sayıs1 açısından da K1000 uygulamasının yine en yüksek verime ulaştığı kök uzunluğunda P2000 ve K2000 ile P4000, yaprak sayısında ise $\mathrm{K}$ hormonsuz ve C1000 uygulamalarının K1000 uygulamasını izlediği sonucuna ulaşılmışır.

Canlılık yüzdesi dışında incelenen tüm özellikler bakımından 1000 ppm İBA+kum uygulamasının diğer tüm uygulamalardan üstün olduğu; en yüksek bitki ağırlığı $(1,26 \mathrm{~cm})$, kök uzunluğu $(4,89 \mathrm{~cm})$, köklenme yüzdesi $(\% 57)$, yaprak sayısı $(6,12$ adet) ve bitki boyu $(4,99 \mathrm{~cm})$ değerlerine K1000 ortamında ulaşıldığ sonucuna varılmıştır. Kum köklendirme ortamında 1000 ppm'den yüksek dozlardaki IBA düzeylerinde bitki ağırlığının azaldığı belirlenmiştir.

Çalışma sonunda \%80 ile en yüksek canl1l1k ve $\% 57$ köklenme oranı ile en yüksek köklenme ortalamasına 1000 ppm kum ortamında ulaşılmıştır. Çalışmada elde edilen \%57'lik köklenme yüzdesi 
düşük görünse de 1400 ile 1770 metre yükseklikte yayılış gösteren bu endemik bitkinin deniz seviyesinde çelikle çoğaltımının gerçekleştirilmesi nedeniyle olumlu bir sonuç olarak ortaya çıkmıştır.

Beş Sideritis türü $S$. condensata, S. congesta, S. leptoclada, S. libanotica ve S. tmolea bitkilerinin vejetatif çoğaltımı üzerine yapılan bir çalışmada İBA ve İAA oksin türevlerinin 250,500 , 750 ve $1000 \mathrm{ppm}$ dozlarında bitkilere $5 \mathrm{dk}$ süreyle uygulanmış, hormonsuz ortamda kök gelişimin gerçekleşmediği, en uygun köklenmenin türlere göre farklılık göstermekle birlikte 750-1000 ppm hormon dozlarından birinin olduğu sonucuna varılmıştır (Gümüşçü ve Gümüşçü, 2014). Çalışmada uygulanan hormon seviyeleri arasında elde edilen 1000 ppm kum ortamdaki sonuçlarla bu çalışmadaki elde edilen sonuçlar paralellik göstermektedir.

\section{Sonuç ve Öneriler}

Kum ortamı, organik madde ve bitki besin madde bakımından fakir olsa da diğer iki ortamla karşılaştırıldığında büyük gözenekli ve infiltrasyon açsından üstündür. Kum ortamının Sarıkız çayı bitkisinin doğal yayılış gösterdiği, infiltrasyon kabiliyeti yüksek toprak isteği ile karşılaştırıldığında elde edilen sonuçlar paralellik göstermektedir. Diğer yandan bitkinin yüksek rakım seviyesinde düşük sıcaklık isteği ile kum ortamının açık renkli olması sebebiyle güneş 1şınlarını yansıtarak koyu renkli ortamlara göre nispeten daha serin ortam ihtiyacını karşıladığı sonucunu çıkarılmaktadır. Perlit ortamı da kum ortamı gibi açı renklidir ancak yüksek adhezyon kuvveti nedeniyle drenaj özelliğinin düşük olması geçirgenlik düzeyini de düşürmektedir. Havalanabilir köklenme ortamı tercih eden bu bitkinin erken dönemdeki canlılık düzeyi açısından hormonsuz perlit ortamı ön plana çıksa da kök gelişimi açısından olumsuz etkisi göstermiştir. Bu çalışma bulgularında görüldüğü üzere Sideritis trojana bitkisi köklenme ortamı olarak en uygun 1000 ppm IBA uygulanarak kum ortamına alınan bitkilerin incelenen parametreler açısından en uygun olduğu sonucu bu bitkinin doğal yaşam olarak tercih ettiği özelliklere de uyum sağladığı sonucuna varılmıştır.

Doğadan toplanan bitkilerin yörede toplayıcılıkla geçimini sağlayan köylülerin yaşam kaynağ olduğu ve göç baskısını bir nebze de dizginlediği unutulmamalıdır. Fakat bu gerçek endemik bitkilerin doğadan yok olmaması için koruma altına alınması gerekliğini ortadan kaldırmaz. Önemli bitkilerin kültüre alınarak sosyoekonomik gelir seviyesi düşük olan yörelerde üretilmesi son derece önemlidir. Sideritis gibi yüksek rakımdaki kireçli arazilerde yetişebilen alternatif tarım ürünler ile değerlendirilmesi dar gelirli ailelerin hane gelirini arttırarak şehre göç önünde bir engel oluşturabilir. Kültüre alınan bitkilerin doğadan toplananlarla karşılaştırıldığında daha yeknesak yapıya sahip olması yanında kayaçlarda bulunan serpantin içeriği yüksek ana kayada ağır metal kontaminasyonunun önüne geçilmesi de mümkündür.

$\mathrm{Bu}$ çalışma sonunda elde edilen bitki popülasyonu ile in vitro ortamda mikroklonal çoğaltım üzerine çalışma yapılmasında yarar olacaktır.

Teşekkür: Katkı ve önerilerinden dolayı Prof. Dr. Cem Ömer EGESEL'e teşekkür ederim.

\section{Kaynaklar}

Çelik, S., Karabacak, E., Uysal, İ., 2008. Plants have been Collected from Mythological Kazdağ (Mt. Ida) National Park, West Turkey by Turkmens and their Folk, Cultural and Social Uses. European Journal of Scientific Research. 19(4):835-843.

Çördük, N., Ak1, C., 2011. Inhibition of browning problem during micropropagation of Sideritis trojana bornm., an endemic medicinal herb of Turkey. Romanian Biotechnological Letters. 16(6):6760-6765.

Fay, M.F., 1992. Conservation of rare and endangered plants using in vitro methods. In Vitro Cell. Dev. Biol. 28: $1-4$.

Gümüşçü, A., Gümüş̧̋̈, G., 2014. Bazı Sideritis (Dağçayı) Türlerinde Çeliklerin Köklenmesine Hormonların Etkisi. Harran Tarım ve Gida Bilimleri Dergisi. 18(2):49-55.

Hofrichter, J., Krohn, M., Schumacher, T., Lange, C., Feistel, B., Walbroel, B., Pahnkea, J., 2016. Sideritis spp. extracts enhance memory and learning in Alzheimer's $\beta$-amyloidosis mouse models and aged C57B1/6 Mice. J Alzheimers Dis. 53(3):967-980.

Kırmızıbekmez, H., Karaca, N., Demirci, B., Demirci, F., 2017. Characterization of Sideritis trojana Bornm. essential oil and its antimicrobial activity. Marmara Pharmaceutical Journal. 21(4):860-865.

Leblebici, Z., Çelik, J., 2014. Kayseri'nin Yahyalı ilçesinde serpantin içeren alanlarda yetişen bazı bitkilerin ağır metal (Co, Cr, $\mathrm{Cu}, \mathrm{Fe}, \mathrm{Ni}, \mathrm{Pb}, \mathrm{Zn})$ içerikleri. Nevşehir Hacı Bektaşi Veli Üniversitesi Fen Bilimleri Enstitüsü Biyoloji Anabilim Dalı Yüksek Lisans Tezi:222. 
ÇOMÜ Zir. Fak. Derg. (COMU J. Agric. Fac.)

2019: 7 (1): 175-179

ISSN: $2147-8384$ / e-ISSN: 2564-6826

doi: $10.33202 /$ comuagri.472635

Önal, A., Acar, N., Eser, F., Çakır, U., 2015. Investigation of the dyeing properties of Sideritis trojana ehrend in the fabrics that pre-treated with willow extract. Journal of New Theory. 8: 92-100.

Öztürk, M., Uysal, I., Karabacak, E., Çelik, S., 2011. Plant species micro endemism, rarity and conservation of pseudo- alpine zone of Kazdaği (Mt. Ida) National Park Turkey. The 2nd International Geography Symposium Geomed 2010. Procedia Social and Behavioral Sciences. 19:778-786.

Satıl, F., Dirmenci, T., Tümen, G., 2006. Kazdağı milli parkının öncelikli koruma alanlarının sınıflandırılması ve önemli bitkileri. Kazdağları II. Ulusal Sempozyumu, Çanakkale: 391-401.

Selvi, S., Dağdelen, A., Kara, S., 2013. Kaz Dağlarından (Balıkesir Edremit) toplanan ve çay olarak tüketilen tıbbi ve aromatik bitkiler. Tekirdağ Ziraat Fakültesi Dergisi. 10(2):26-33.

Şahin, F.P., Duman, H., Çalış, İ., Ezer, N., 2005. Botanical properties of a herbal tea: Sideritis stricta Boiss. Heldr. apud Bentham. FABAD J. Pharm. 30:10-195.

Topçu, G., Gören, A., Kılıç, T., Kemal, Y., Tümen, G., 2001. Diterpenes from Sideritis trojana. Natural Product Letters. 16(1):33-37.

Uysal, İ., Öztürk, M., Pirdal, M., 1991. Sideritis trojana Bomm. endemik türünün morfolojisi, anatomisi ve ekolojisi. Turkish Journal of Botany. 15:371-379.

Uysal, İ., 2010. An overview of plant diversity of Kazdagi (Mt. Ida) Forest National Park. Turkish Journal of Environmental Biology. 31:141-147. 